\title{
MOFs-Derived Zn-Based Catalysts in Acetylene Acetoxylation
}

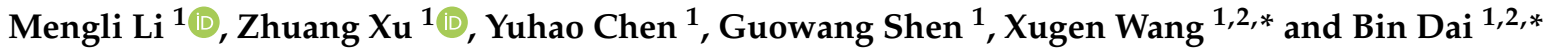 \\ 1 School of Chemistry and Chemical Engineering, Shihezi University, Shihezi 832000, China; \\ 20192007095@stu.shzu.edu.cn (M.L.); 20182007103@stu.shzu.edu.cn (Z.X.); chenyuhao@stu.shzu.edu.cn (Y.C.); \\ 20202107050@stu.shzu.edu.cn (G.S.) \\ 2 Key Laboratory for Green Processing of Chemical Engineering of Xinjiang Bingtuan, Shihezi 832000, China \\ * Correspondence: wxgen@shzu.edu.cn (X.W.); db_tea@shzu.edu.cn (B.D.); Tel.: +86-993-2057270 (B.D.); \\ Fax: +86-993-2057210 (B.D.)
}

\begin{abstract}
Metal-organic frameworks (MOFs)-derived materials with a large specific surface area and rich pore structures are favorable for catalytic performance. In this work, MOFs are successfully prepared. Through pyrolysis of MOFs under nitrogen gas, zinc-based catalysts with different active sites for acetylene acetoxylation are obtained. The influence of the oxygen atom, nitrogen atom, and coexistence of oxygen and nitrogen atoms on the structure and catalytic performance of MOFsderived catalysts was investigated. According to the results, the catalysts with different catalytic activity are $\mathrm{Zn}-\mathrm{O}-\mathrm{C}(33 \%), \mathrm{Zn}-\mathrm{O} / \mathrm{N}-\mathrm{C}(27 \%)$, and $\mathrm{Zn}-\mathrm{N}-\mathrm{C}(12 \%)$. From the measurements of X-ray photoelectron spectroscopy (XPS), it can be confirmed that the formation of different active sites affects the electron cloud density of zinc. The electron cloud density of zinc affects the ability to attract $\mathrm{CH}_{3} \mathrm{COOH}$, which makes catalysts different in terms of catalytic activity.
\end{abstract}

Keywords: metal-organic frameworks; heteroatoms; acetylene acetoxylation

check for updates

Citation: Li, M.; Xu, Z.; Chen, Y.; Shen, G.; Wang, X.; Dai, B. MOFs-Derived Zn-Based Catalysts in Acetylene Acetoxylation. Nanomaterials 2022, 12, 98. https:// doi.org/10.3390/nano12010098

Academic Editor: Filipe

M.L. Figueiredo

Received: 15 November 2021

Accepted: 24 December 2021

Published: 29 December 2021

Publisher's Note: MDPI stays neutral with regard to jurisdictional claims in published maps and institutional affiliations.

Copyright: (C) 2021 by the authors. Licensee MDPI, Basel, Switzerland. This article is an open access article distributed under the terms and conditions of the Creative Commons Attribution (CC BY) license (https:// creativecommons.org/licenses/by/ $4.0 /)$.

\section{Introduction}

Vinyl acetate (VAc) is a significant chemical raw material globally, which is a colorless and flammable liquid with a sweet ether taste. VAc is mainly used to produce polyvinyl acetate (PVAc), polyvinyl alcohol (PVA), vinyl acetate-ethylene copolymer emulsion (VAE), ethylene-vinyl acetate resin (EVA), and other necessary downstream chemical raw materials, and it has also been widely used in coatings, adhesives, vinylon, and other fields [1-3]. At present, vinyl acetate is manufactured from petroleum ethylene and calcium carbide acetylene [4]. Given the fact that China features a coal-rich, oil-poor, and low-gas energy structure [5,6], calcium carbide acetylene is the primary source to produce vinyl acetate.

After continuous exploration and research by predecessors, it is found that the catalyst prepared with zinc as the active component and activated carbon as the carrier shows better catalytic performance in the production of vinyl acetate by the acetylene method [7-9]. Although it has been used in industry, there are still many shortcomings, such as a low conversion rate, easy agglomeration, deactivation of active components, and carbon deposition on catalysts. To deal with these problems, He et al. improved the activity and stability of the catalyst by doping bimetallic $\mathrm{Zn}-\mathrm{Ni}$ [10] and $\mathrm{Zn}-\mathrm{Co}$ [11]. Some researchers prepared $\mathrm{V}_{2} \mathrm{O}_{5}-\mathrm{ZnO}$ and $\mathrm{Fe}_{2} \mathrm{O}_{3}-\mathrm{ZnO}$ composite catalysts to extend the service life of the catalyst, but the results were not satisfactory $[12,13]$. There were also researchers who used nitrogen [14], oxygen [15], and boron [16] to modify activated carbon for changing the electron cloud density around zinc by changing the defect degree of the carrier, and then improving the reaction activity of the catalysts. It has been proven that many functional groups exist on the activated carbon support. However, little is known about how they affect the catalyst performance. Many scholars hold different views $[15,17]$, rather than a uniform conclusion.

MOFs are crystalline nanoporous materials with a framework structure composed of transition metal ions and organic ligands [18], with the metal components dispersed one 
by one through organic ligands. On account of the large specific surface area, abundant pore structure, and surface defects of MOFs, MOFs have become a research hotspot in the fields of gas storage, gas adsorption, separation, sensors, drug controllable release, and catalytic reactions [19-25]. Because of their excellent chemical and thermal stability, MOFs are also used as a template or precursor for the preparation of porous carbon materials or metal composite materials [26]. By changing the types of organic ligands, catalysts doped with different elements can be prepared by simple calcination. Herein, we speculate that MOFs-derived materials can be used for catalyzing acetylene acetoxylation.

At present, the relationship between the active component and the carrier during the reaction process is not clear. This study mainly used MOFs as precursors of catalysts, after calcination under inert atmosphere; $\mathrm{Zn}-\mathrm{O}-\mathrm{C}, \mathrm{Zn}-\mathrm{O} / \mathrm{N}-\mathrm{C}$, and $\mathrm{Zn}-\mathrm{N}-\mathrm{C}$ catalysts with different active sites were obtained, respectively; and the influence of different zinc coordination modes on the reaction was investigated.

\section{Materials and Methods}

\subsection{Materials}

Zinc nitrate hexahydrate $\left(\mathrm{Zn}\left(\mathrm{NO}_{3}\right)_{2} \cdot 6 \mathrm{H}_{2} \mathrm{O}, 99.0 \%\right)$, terephthalic acid $\left(\mathrm{H}_{2} \mathrm{BTC}, 99.0 \%\right)$, $\mathrm{N}, \mathrm{N}$-dimethylformamide (DMF, 99.0\%), dimethylimidazole (2-MI, 98.0\%), methanol (99.5\%), triethylenediamine (TEDA, 99.0\%), and pyridine (PD, 99.5\%), all reagents, were of analytical grade; no further purification was required.

\subsection{Catalysts' Preparation}

\subsubsection{Preparation of Zn-O-C Catalyst Using MOF5 Precursor}

MOF5 was prepared according to the method reported in the literature [27]. First, $2.23 \mathrm{~g}$ of $\mathrm{Zn}\left(\mathrm{NO}_{3}\right)_{2} \cdot 6 \mathrm{H}_{2} \mathrm{O}$ and $0.67 \mathrm{~g}$ of $\mathrm{H}_{2} \mathrm{BDC}$ were dissolved in $100 \mathrm{~mL}$ DMF solution, respectively; after the raw materials had dissolved entirely, the solution containing $\mathrm{Zn}\left(\mathrm{NO}_{3}\right)_{2} \cdot 6 \mathrm{H}_{2} \mathrm{O}$ was slowly poured into the solution containing $\mathrm{H}_{2} \mathrm{BTC}$. After the mixing, the solution was transparent and then underwent centrifugal collection at a speed of $800 \mathrm{r} / \mathrm{min}$, then the solutions were poured into a $200 \mathrm{~mL}$ poly tetra fluoroethylene (PTFE) hydrothermal reactor autoclave and kept at $140{ }^{\circ} \mathrm{C}$ for $24 \mathrm{~h}$. After cooling to room temperature, the solution was centrifuged at $8000 \mathrm{r} / \mathrm{min}$ and washed by DMF three times. To remove the unreacted solvent molecules, the sample was treated with ethanol overnight, and then dried at $80^{\circ} \mathrm{C}$ to obtain the MOF5 precursor.

Secondly, the prepared MOF5 was calcined at $450{ }^{\circ} \mathrm{C}$ for $4 \mathrm{~h}$ with a heating rate of $5{ }^{\circ} \mathrm{C} / \mathrm{min}$ in a tube furnace under the nitrogen atmosphere. Then, the required catalyst could be obtained by natural cooling to room temperature and was named $\mathrm{Zn}-\mathrm{O}-\mathrm{C}$.

\subsubsection{Preparation of $\mathrm{Zn}-\mathrm{O} / \mathrm{N}-\mathrm{C}$ Catalyst Using TEDA-PD Precursor}

The preparation method was based on the synthesis of Ni-MOF [28]. The preparation details are as follows: $2.38 \mathrm{~g} \mathrm{Zn}\left(\mathrm{NO}_{3}\right)_{2} \cdot 6 \mathrm{H}_{2} \mathrm{O}$ was dispersed in $100 \mathrm{~mL}$ DMF solution, and $1.33 \mathrm{~g} \mathrm{H}_{2} \mathrm{BTC}$ and $0.6 \mathrm{~g}$ TEDA were dispersed in $100 \mathrm{~mL}$ DMF solution, after the complete dissolution, and the $\mathrm{Zn}\left(\mathrm{NO}_{3}\right)_{2} \cdot 6 \mathrm{H}_{2} \mathrm{O}$ solution was slowly poured into the solution containing $\mathrm{H}_{2} \mathrm{BDC}$ and TEDA, and then stirred for $15 \mathrm{~min}$. Next, a certain amount of PD slowly poured, and then stirred for $12 \mathrm{~h}$ in an oil bath at $100{ }^{\circ} \mathrm{C}$. When it was cooled down to room temperature, the precipitate was collected by centrifugation and washed with DMF solvent three times, and subsequently it was dried under vacuum at $80^{\circ} \mathrm{C}$ for $10 \mathrm{~h}$; the precursor was obtained and named TEDA-PD. The catalyst obtained after $450{ }^{\circ} \mathrm{C}$ calcination was named $\mathrm{Zn}-\mathrm{O} / \mathrm{N}-\mathrm{C}$.

\subsubsection{Preparation of Zn-N-C Catalyst Using 2-Methylimidazole Zinc Salt (ZIF8) Precursor}

ZIF8 was prepared by the method reported in the literature [29]. Here, $2.23 \mathrm{~g}$ and $2.46 \mathrm{~g}$ of $\mathrm{Zn}\left(\mathrm{NO}_{3}\right)_{2} \cdot 6 \mathrm{H}_{2} \mathrm{O}$ and 2-MI, respectively, were added into $40 \mathrm{~mL}$ methanol solution; when they were completely dissolved, the $\mathrm{Zn}\left(\mathrm{NO}_{3}\right)_{2} \cdot 6 \mathrm{H}_{2} \mathrm{O}$ solution was slowly poured into the 2-MI solution, and then stirred for $24 \mathrm{~h}$ at $500 \mathrm{r} / \mathrm{min}$. The precipitate was collected 
by centrifugation at a speed of 10,000 r/min, washed with methanol three times, and then dried in a vacuum drying oven at $80{ }^{\circ} \mathrm{C}$ for $12 \mathrm{~h}$. Finally, the sample was ground to a powder to obtain ZIF8. The catalyst obtained after $550{ }^{\circ} \mathrm{C}$ calcination was named Zn-N-C.

\subsection{Catalysts Characterization}

The scanning electron microscope (SEM, JEOL, JSM-6490LV, Tokyo, Japan) instrument was used to image the material. The Fourier transform infrared (FT-IR, Thermo Scientific, Nicolet IS10, Waltham, MA, USA) spectra was used to identify chemical species. The specific surface area, pore volume, and pore size of the sample were recorded by an automatic fast physical adsorption analyzer (BET, Micromeritics, ASAP 2460, GA, USA), degased at $150{ }^{\circ} \mathrm{C}$ for $5 \mathrm{~h}$, and then analyzed under liquid nitrogen at $-196{ }^{\circ} \mathrm{C}$ to test. X-ray photoelectron spectroscopy (XPS, Thermo Fisher Scientific, ESCAlAB 250Xi, Waltham, MA, USA) was used to analyze the chemical states of elements. The thermogravimetric (TG, NETZSCH, STA 449F3, Selb, Germany) was used to test the thermal stability of the samples. The temperature-programmed desorption (TPD, Micromeritics, ASAP 2720, Norcross, GA, USA) experiment was used to determine the gas adsorption capacity and adsorption strength of the catalysts. Inductively coupled plasma mass spectrometry (ICP, Agilent, ICPOES730, Santa Clara, CA, USA) was used to test the zinc content of the samples, which used argon as the carrier gas.

\subsection{Catalyst Evaluation}

A self-assembled fixed-bed reaction device was used for the activity test. A stainless steel pipe with an inner diameter of $10 \mathrm{~mm}$ was filled with quartz sand and quartz wool at the bottom of the reaction tube for paving, and a certain amount of catalyst was added. Reaction conditions: heating temperature was set at $220^{\circ} \mathrm{C}$, the gas hourly space velocity of $\mathrm{C}_{2} \mathrm{H}_{2}$ (GHSV) was $500 \mathrm{~h}^{-1}$ and the molar ratio of $\mathrm{C}_{2} \mathrm{H}_{2} / \mathrm{CH}_{3} \mathrm{COOH}$ was 1:2.45. Before the reaction started, $\mathrm{CH}_{3} \mathrm{COOH}$ was used to activate the catalysts for $0.5 \mathrm{~h}$, and $\mathrm{C}_{2} \mathrm{H}_{2}$ was introduced to start the reaction. Then, samples were taken every $1 \mathrm{~h}$, using GC-9A (Shimadzu, Tokyo, Japan) gas chromatography to analyze the content of the obtained product, and the chromatographic column model was a PEG/20000 (Zhonghuida, Dalian, China) packed column.

\section{Results and Discussion}

\subsection{Catalytic Performance Evaluation}

Different active sites modes can be formed by doping different organic ligands. In this study, nine kinds of zinc-based MOF materials were prepared using organic ligands, including the following: 2-MI, $\mathrm{H}_{2} \mathrm{BDC}, \mathrm{H}_{2} \mathrm{BDC}\left(\mathrm{NH}_{2}\right), \mathrm{H}_{2} \mathrm{BDC}\left(\mathrm{NO}_{2}\right)$, TEDA, TETA (triethylenetetramine), and PD. The microscopic morphologies of eight kinds of materials are shown in Figure S1, and it can be observed that different structures such as petal-like, cube, cuboid, and sheet-like structures, respectively, were formed with the addition of different organic ligands. In a humid environment, water molecules will replace the organic ligands in MOFs, thereby destroying the crystal structure [30]; to remove the excess $\mathrm{H}_{2} \mathrm{BDC}$, the organic matter in the precursor was volatilized and transformed into a loose porous structure, so we calcined MOFs to prepare catalysts. The conversion rate curves are shown in Figure S2, and it can be found that there is a certain difference in catalysts' conversion. On this basis, we selected three kinds of materials with different zinc coordination modes, reactivity (Figure 1) and similar specific surface area (Table S1) to prepare Zn-O-C, Zn-O/N$\mathrm{C}$, and $\mathrm{Zn}-\mathrm{N}-\mathrm{C}$ catalysts with three-dimensional structures using MOF5, TEDA-PD, and ZIF8, respectively, as precursors. 


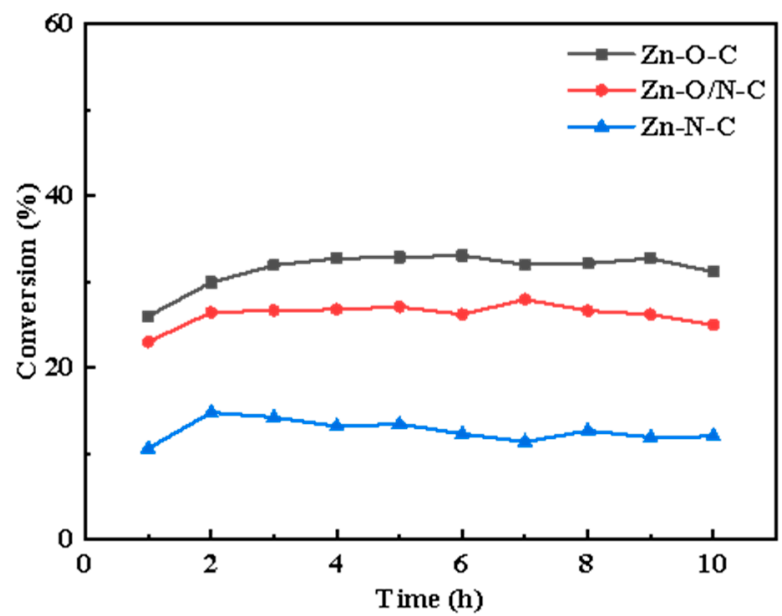

Figure 1. The conversion rate curves of $\mathrm{Zn}-\mathrm{O}-\mathrm{C}, \mathrm{Zn}-\mathrm{O} / \mathrm{N}-\mathrm{C}$, and $\mathrm{Zn}-\mathrm{N}-\mathrm{C}$ catalysts over time, respectively.

MOF5 is one of the typical MOFs materials, and it uses zinc as the central metal and $\mathrm{H}_{2} \mathrm{BDC}$ as the organic ligand. First, four zinc atoms and an oxygen atom from $\mathrm{H}_{2} \mathrm{BDC}$ are connected to form the secondary structural unit $\mathrm{Zn}_{4} \mathrm{O}(\mathrm{BDC})_{3}$ [31] (Figure 2a); this second structural unit is in the shape of an octahedron, and metal ions are wrapped inside as the frame nodes. Because of its strong interaction force, the entire frame structure is more stable, and $\mathrm{Zn}_{4} \mathrm{O}(\mathrm{BDC})_{3}$ is connected with the ligand to form a three-dimensional skeleton with micropores. By adding other organic ligands, such as TEDA and PD, the coordination form of zinc can be changed into $\mathrm{Zn}-\mathrm{N}$ and $\mathrm{Zn}-\mathrm{O}$, named as TEDA-PD. As shown in Figure $2 \mathrm{~b}$, TEDA-PD consists of a pair of zinc ions connected with oxygen atoms from four $\mathrm{H}_{2} \mathrm{BTC}$ in the horizontal direction and nitrogen atoms from TEDA in the vertical direction; the vertical connection was terminated using PD as an inhibitor and the thickness of the three-position frame can be controlled by adjusting the amount of PD added. In another case, in Figure 2c, ZIF8 possesses a zeolite imidazole ester skeleton structure, as an important type of MOFs materials; zinc acts as the central metal, while 2-MI acts as the organic ligand. Zinc is connected to four nitrogen atoms from 2-MI to form a three-dimensional cage structure. Both oxygen and nitrogen atoms have relatively strong electronegativity and, when they are coordinated with zinc, they will attract electrons around zinc. As different zinc coordination shows variation in the electron cloud density around zinc, this would affect the ability of the catalysts to attract $\mathrm{CH}_{3} \mathrm{COOH}$, and finally lead to a different activity in the catalytic reaction.

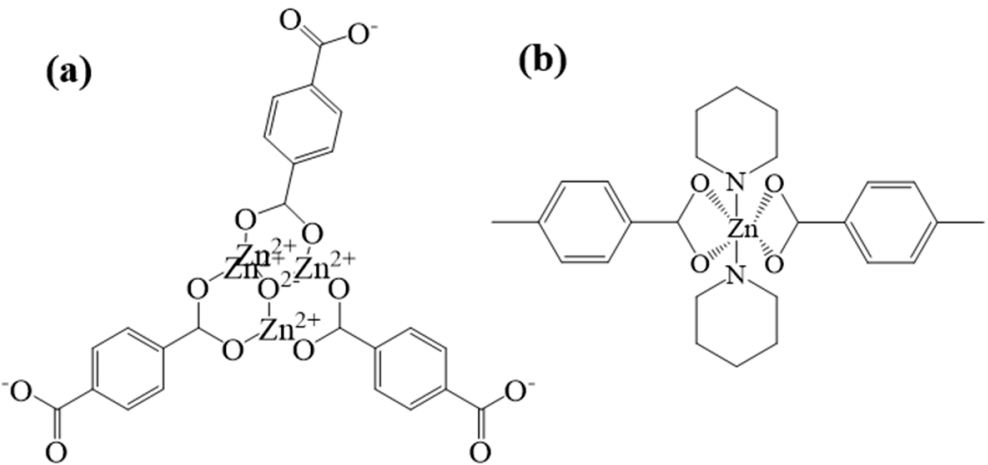

(c)

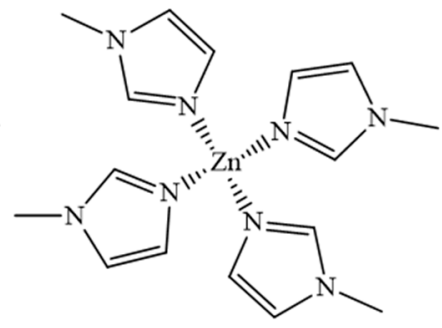

Figure 2. Schematic diagram of chemical structures for MOF5 (a), TEDA-PD (b), and ZIF8 (c).

Figure $3 \mathrm{a}-\mathrm{c}$ shows the synthesis processes. The catalytic activity sequence is $\mathrm{Zn}-\mathrm{O}-\mathrm{C}$ (33\%), Zn-O/N-C (27\%), and Zn-N-C (12\%); Zn-O-C shows better catalytic activity, and related characterizations are analyzed in the following section to explore the mechanisms for the different activities. 
(a)

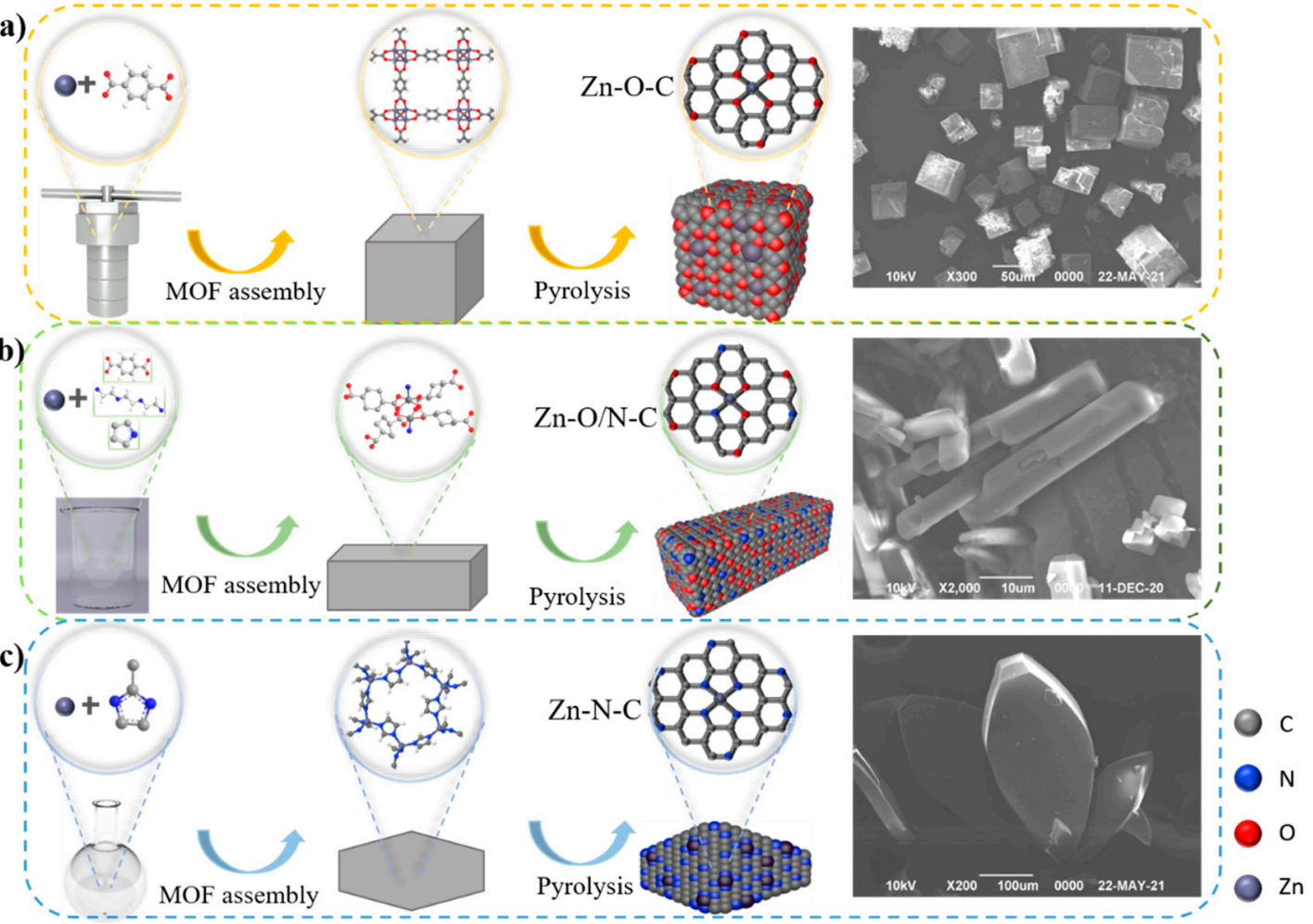

Figure 3. Schematic diagrams of the synthesis process and the SEM images of MOF5 (a), TEDA-PD (b), and ZIF8 (c), respectively.

The infrared spectra of MOF5 and ZIF8 in Figure 4a are consistent with that of the reported literature [32,33], indicating that MOF5 and ZIF8 were successfully prepared. Among them, the absorption peak at $3447 \mathrm{~cm}^{-1}$ belongs to the $\mathrm{O}-\mathrm{H}$ vibration, which was caused by physical adsorption of moisture in the atmosphere. The two sharp peaks around $2354 \mathrm{~cm}^{-1}$ can be attributed to $\mathrm{C}=\mathrm{O}$ vibration, which came from the absorption of $\mathrm{CO}_{2}$ in the atmosphere. The peaks at $1644 \mathrm{~cm}^{-1}$ and $1382 \mathrm{~cm}^{-1}$ in MOF5 can be assigned to the symmetrical and asymmetrical stretching vibrations of $\mathrm{O}-\mathrm{C}=\mathrm{O}$ bond of the carboxyl group in $\mathrm{H}_{2} \mathrm{BDC}$. The absorption peak of $\mathrm{Zn}-\mathrm{O}$ bond in $\mathrm{Zn}_{4} \mathrm{O}$ tetrahedron is located at $529 \mathrm{~cm}^{-1}$. For the stretching vibration of the $\mathrm{C}=\mathrm{N}$ bond at $1585 \mathrm{~cm}^{-1}$ in $\mathrm{ZIF} 8$, the band in the range of $500-1500 \mathrm{~cm}^{-1}$ is mainly caused by the bending vibration and stretching vibration in the imidazole ring.

According to the thermogravimetric spectra in Figure 4b, MOF5 began to collapse at about $500{ }^{\circ} \mathrm{C}$, so $450{ }^{\circ} \mathrm{C}$ was chosen for calcination to avoid the collapse of MOFs. ZIF8 shows better thermal stability, which starts to decompose at about $600{ }^{\circ} \mathrm{C}$; the specific surface area of the ZIF8 obtained by calcination at $450{ }^{\circ} \mathrm{C}$ was $11.77 \mathrm{~m}^{2} / \mathrm{g}$. In comparison, ZIF8 was prepared at $550{ }^{\circ} \mathrm{C}$ to obtain similar specific surface areas to that of two other samples. MOF5, TEDA-PD, and ZIF8 were calcined to form catalysts rich in Zn-O-C, Zn$\mathrm{O} / \mathrm{N}-\mathrm{C}$, and $\mathrm{Zn}-\mathrm{N}-\mathrm{C}$ bonds, respectively; the BET (obtained by the Brunauer-Emmer-Teller algorithm) specific surface areas do not show much differences, with values of 301.40, 343.04 , and $331.10 \mathrm{~m}^{2} / \mathrm{g}$ (Figure $4 \mathrm{c}$ ), respectively. The adsorption and desorption curves (Figure 4d) show obvious hysteresis loops in all samples, indicating the existence of both micropores and mesopores. 

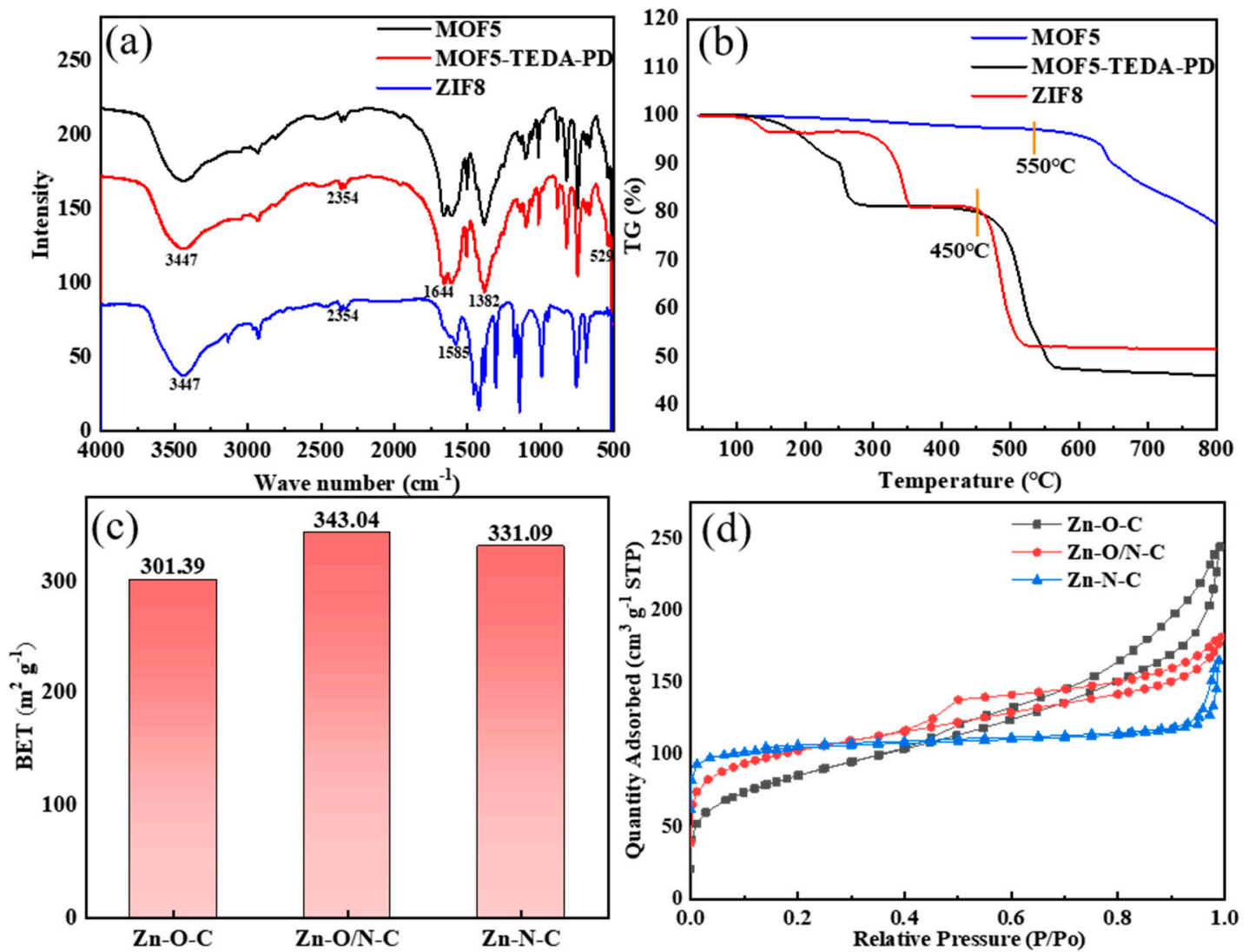

Figure 4. FT-IR spectra (a) and TG spectra (b) of MOF5, TEDA-PD, and ZIF8. Specific surface areas (c) and adsorption and desorption curves (d) of MOF5, TEDA-PD, and ZIF8 after calcination.

In order to further verify the different coordination forms of zinc in different catalysts, we carried out an XPS test. From the XPS spectra in Figure 5a, it can be seen that the three materials all contain zinc, oxygen, and carbon. It is difficult to observe the presence of nitrogen in $\mathrm{Zn}-\mathrm{O} / \mathrm{N}-\mathrm{C}$, implying that $\mathrm{Zn}-\mathrm{O} / \mathrm{N}-\mathrm{C}$ mainly consists of $\mathrm{Zn}-\mathrm{O}-$ based coordination as well as a few $\mathrm{Zn}-\mathrm{N}$ bonds; the element contents of each catalyst are shown in Figure S3a. Figure 5b-d displays high-resolution spectra of $\mathrm{Zn} \mathrm{2p}, \mathrm{O} 1 \mathrm{~s}$, and $\mathrm{N}$ 1s of $\mathrm{Zn}-\mathrm{O}-\mathrm{C}, \mathrm{Zn}-\mathrm{O} / \mathrm{N}-\mathrm{C}$, and $\mathrm{Zn}-\mathrm{N}-\mathrm{C}$ catalysts. In Figure $5 \mathrm{~b}$, the binding energies of $\mathrm{Zn} 2 \mathrm{p}_{1 / 2}$ and $\mathrm{Zn} 2 \mathrm{p}_{3 / 2}$ for $\mathrm{Zn}-\mathrm{O}-\mathrm{C}$ [34], Zn-N-C [35], and $\mathrm{Zn}-\mathrm{O} / \mathrm{N}-\mathrm{C}$ are $1021.9 \mathrm{eV}$ and $1045.0 \mathrm{eV}$, $1021.7 \mathrm{eV}$ and $1044.6 \mathrm{eV}$, and $1022.0 \mathrm{eV}$ and $1045.1 \mathrm{eV}$, respectively, indicating the existence of $\mathrm{Zn}^{2+}$ in the catalysts. Moreover, the values of binding energy positions for three catalysts are $\mathrm{Zn}-\mathrm{O} / \mathrm{N}-\mathrm{C}>\mathrm{Zn}-\mathrm{O}-\mathrm{C}>\mathrm{Zn}-\mathrm{N}-\mathrm{C}$, showing that the electron cloud density around zinc for $\mathrm{Zn}-\mathrm{O} / \mathrm{N}-\mathrm{C}$ is the largest, while it is the smallest for $\mathrm{Zn}-\mathrm{N}-\mathrm{C}$. The coordination state of the ligands around the zinc atoms is different [36], which is caused by the difference in the ability of oxygen and nitrogen atoms [37] to attract electrons. The electronegativity of oxygen atom is greater than that of nitrogen, which makes more electrons in $\mathrm{Zn}-\mathrm{O}-\mathrm{C}$ bias towards oxygen and leads to a reduction in the electron cloud density around zinc. It can be found that the binding energy position of $\mathrm{Zn} 2 \mathrm{p}$ moves to the high field direction. The electron cloud density around zinc of $\mathrm{Zn}-\mathrm{O} / \mathrm{N}-\mathrm{C}$ is large, because zinc is connected to four oxygen atoms in the horizontal direction, while having more nitrogen connections in the vertical direction than $\mathrm{Zn}-\mathrm{O}-\mathrm{C}$, so the peak for $\mathrm{Zn} 2 \mathrm{p}$ shifts to a higher binding energy. The shifts in the Zn $2 p$ binding energy positions of the three catalysts indicate that zinc has different coordination modes. The $\mathrm{O} 1 \mathrm{~s}$ pattern in Figure $5 \mathrm{c}$ shows that the binding energy value of $\mathrm{Zn}-\mathrm{O}-\mathrm{C}$ is the smallest. O 1s can be fitted into three peaks at $530.6 \mathrm{eV}, 531.2 \mathrm{eV}$, and $532.5 \mathrm{eV}$. The first peak at $530.6 \mathrm{eV}$ refers to the oxygen ion from the $\mathrm{Zn}-\mathrm{O}$ bond in the lattice of $\mathrm{ZnO}$ [37], leading to zinc atoms existing in the form $\mathrm{Zn}-\mathrm{O}$ [38]. The second peak at $531.2 \mathrm{eV}$ is associated with the form of $\mathrm{OH}$ existing on the catalysts [39]. The third peak 
at $532.5 \mathrm{eV}$ is related to the chemisorbed oxygen on the catalysts [40]. This implies that the three catalysts have different forms of oxygen presence. Compared with Figure S3b, in which $C 1 \mathrm{~s}$ is basically indistinguishable, this indicates that carbon atom does not affect the bonding of zinc. Next, the $\mathrm{N}$ 1s peak splitting of $\mathrm{Zn}-\mathrm{N}-\mathrm{C}$ and $\mathrm{Zn}-\mathrm{O} / \mathrm{N}-\mathrm{C}$ catalysts is presented in Figure $5 \mathrm{~d}$; the $\mathrm{N}$ 1s peak of $\mathrm{Zn}-\mathrm{N}-\mathrm{C}$ can be fitted into two sub-peaks, located at $398.6 \mathrm{eV}$ and $399.5 \mathrm{eV}$, representing pyridine nitrogen and metal nitrogen, respectively. Compared with the $\mathrm{Zn}-\mathrm{N}-\mathrm{C}$ catalyst, the nitrogen content in $\mathrm{Zn}-\mathrm{O} / \mathrm{N}-\mathrm{C}$ is much smaller, showing that the catalyst is mainly coordinated by $\mathrm{Zn}-\mathrm{O}$ bonds, and part of the metal nitrogen was replaced by graphite nitrogen (400.9 eV) [41], so the content of metal nitrogen reduced accordingly.
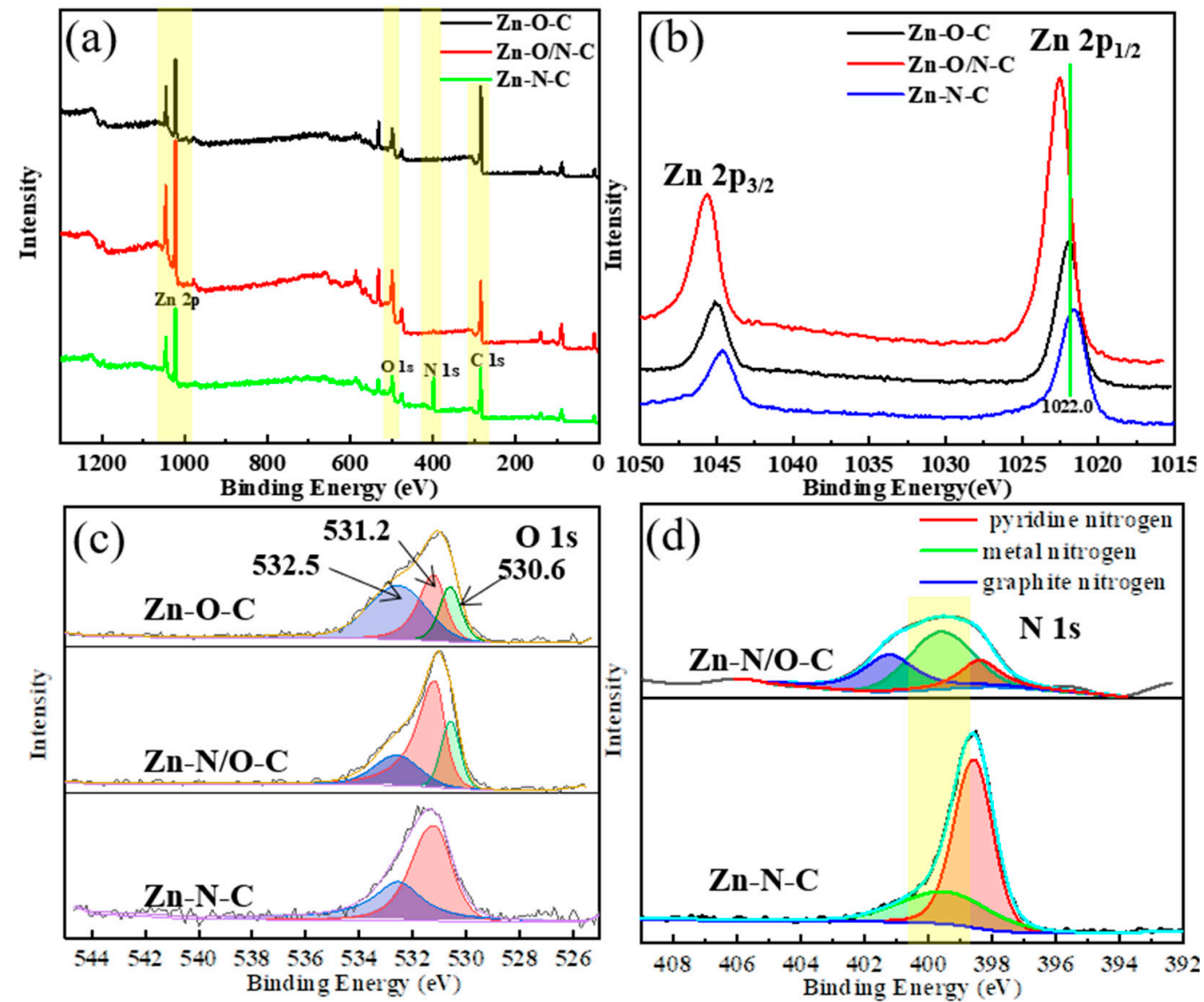

Figure 5. XPS pattern (a) and high-resolution XPS spectra of Zn $2 p(\mathbf{b}), \mathrm{O} 1 \mathrm{~s}$ (c), and $\mathrm{N}$ 1s (d) of $\mathrm{Zn}-\mathrm{O}-\mathrm{C}, \mathrm{Zn}-\mathrm{O} / \mathrm{N}-\mathrm{C}$, and Zn-N-C.

Then, the TPD tests of Zn-O-C, Zn-O/N-C, and Zn-N-C were carried out to observe the adsorption characteristics of the catalysts to the reactants, as shown in Figure 6 . The area of the desorption peak represents the adsorption capacity of the reactant, and the desorption temperature indicates the adsorption strength of the reactant. It can be seen that peak temperatures of the catalysts for $\mathrm{C}_{2} \mathrm{H}_{2}$ are basically the same, proving that there is no difference in their adsorption strength for $\mathrm{C}_{2} \mathrm{H}_{2}$. The off-peak areas of $\mathrm{Zn}-\mathrm{O}-\mathrm{C}$ and $\mathrm{Zn}-\mathrm{N}-\mathrm{C}$ are mostly the same, while the off-peak area of $\mathrm{Zn}-\mathrm{O} / \mathrm{N}-\mathrm{C}$ is the smallest. Although $\mathrm{Zn}-\mathrm{O} / \mathrm{N}-\mathrm{C}$ has the smallest adsorption of $\mathrm{C}_{2} \mathrm{H}_{2}$, the catalytic activity is not very different from $\mathrm{Zn}-\mathrm{O}-\mathrm{C}$, which shows that the adsorption amount of $\mathrm{C}_{2} \mathrm{H}_{2}$ has little effect on the catalytic activity of the catalysts. The de-peaking temperatures of $\mathrm{Zn}-\mathrm{O}-\mathrm{C}, \mathrm{Zn}-\mathrm{O} / \mathrm{N}-\mathrm{C}$, and $\mathrm{Zn}-\mathrm{O}-\mathrm{C}$ for the catalysts are 335,349 , and $407^{\circ} \mathrm{C}$, respectively, indicating that the Zn-N-C catalyst needs a higher temperature to desorb $\mathrm{CH}_{3} \mathrm{COOH}$. Comparing the off-peak area, $\mathrm{Zn}-\mathrm{O} / \mathrm{N}-\mathrm{C}>\mathrm{Zn}-\mathrm{O}-\mathrm{C}>\mathrm{Zn}-\mathrm{N}-\mathrm{C}$, it shows that $\mathrm{Zn}-\mathrm{O} / \mathrm{N}-\mathrm{C}$ has the largest adsorption capacity for $\mathrm{CH}_{3} \mathrm{COOH}$, while $\mathrm{Zn}-\mathrm{N}-\mathrm{C}$ has the smallest adsorption capacity for $\mathrm{CH}_{3} \mathrm{COOH}$; the 
smaller electron cloud density leads to easier attraction of $\mathrm{CH}_{3} \mathrm{COOH}$, which corresponds to the position of the $\mathrm{Zn} 2 \mathrm{p}$ binding energy in the XPS characterization [42].
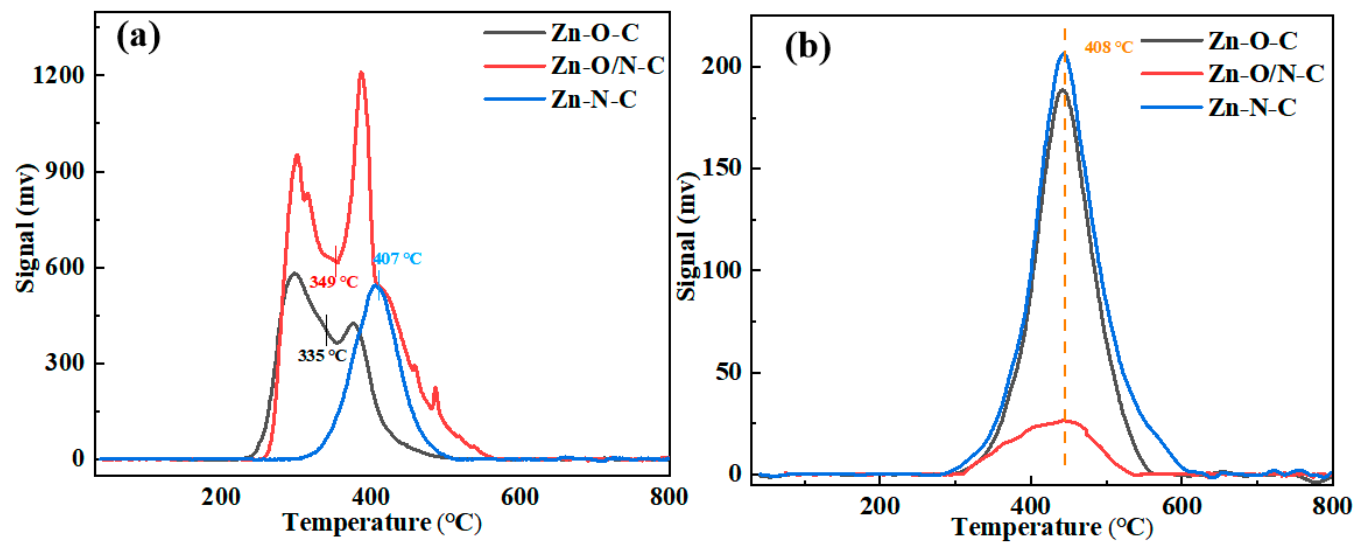

Figure 6. TPD analysis of $\mathrm{Zn}-\mathrm{O}-\mathrm{C}, \mathrm{Zn}-\mathrm{O} / \mathrm{N}-\mathrm{C}$, and $\mathrm{Zn}-\mathrm{N}-\mathrm{C}$ : (a) $\mathrm{CH}_{3} \mathrm{COOH}$ and (b) $\mathrm{C}_{2} \mathrm{H}_{2}$.

\subsection{Performance of Catalysts for Acetylene Acetoxylation}

At present, there are four mechanisms of catalyzing acetylene acetoxylation, including $\mathrm{C}_{2} \mathrm{H}_{2}$ first absorbed by the catalyst adsorption mechanism, $\mathrm{CH}_{3} \mathrm{COOH}$ first absorbed by the catalyst adsorption mechanism, the acid catalysis mechanism, and the carbonyl promotion mechanism [3]. According to our experiments, we have found that passing $\mathrm{C}_{2} \mathrm{H}_{2}$ in the reaction will deactivate the catalyst. Therefore, we prefer $\mathrm{CH}_{3} \mathrm{COOH}$ first absorbed by the catalyst; the reaction process is shown in Figure 7. First, the active component is combined with $\mathrm{CH}_{3} \mathrm{COOH}$ molecules to form zinc acetate (Figure $\mathrm{S} 4$ demonstrates the chemical state of zinc), then $\mathrm{C}_{2} \mathrm{H}_{2}$ molecules are adsorbed for reaction and, finally, $\mathrm{CH}_{3} \mathrm{COOCHCH}_{2}$ is generated after the reaction.
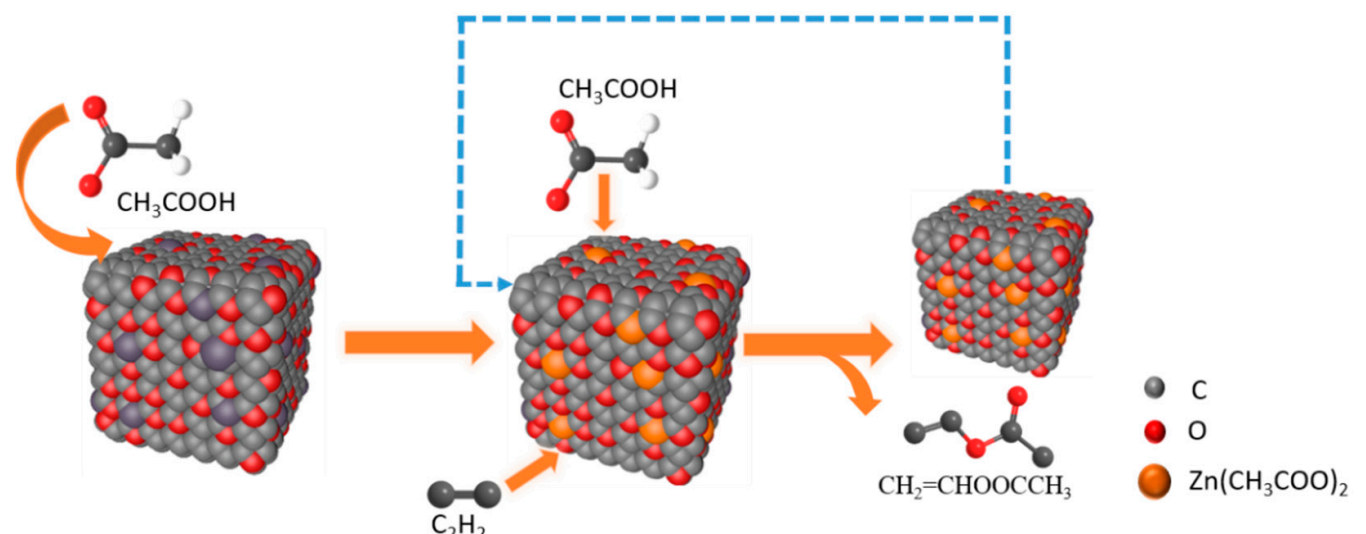

Figure 7. Reaction flow diagram taking $\mathrm{Zn}-\mathrm{O}-\mathrm{C}$ as an example.

According to the previous analysis, the main factor affecting their activity is the coordination mode of zinc. When the $\mathrm{Zn}-\mathrm{N}$ bond exists, the electron cloud density around zinc is stronger, which can be proved by the position shift of XPS Zn 2p (Zn 2p binding energy position $\mathrm{Zn}-\mathrm{N}<\mathrm{Zn}-\mathrm{O}$ ). The increase in the electron cloud density around zinc weakens the attraction for $\mathrm{CH}_{3} \mathrm{COOH}$ molecules, so it is difficult to achieve better catalytic activity. At the same time, it can be found from the TPD spectra that the presence of $\mathrm{Zn}-\mathrm{N}$ bonds strengthens the binding force of the catalyst and $\mathrm{CH}_{3} \mathrm{COOH}$. When $\mathrm{CH}_{3} \mathrm{COOH}$ molecules are adsorbed on both sides of the active component at the same time, it is difficult to desorb, which hinders the subsequent reaction. From the TPD diagram of Figure S5, it can be found that $\mathrm{Zn}-\mathrm{N}-\mathrm{C}$ has a larger adsorption capacity for $\mathrm{CH}_{3} \mathrm{COOCHCH}_{2}$ than that of $\mathrm{Zn}-\mathrm{O}-\mathrm{C}$, which further proves that $\mathrm{CH}_{3} \mathrm{COOH}$ on the $\mathrm{Zn}-\mathrm{N}-\mathrm{C}$ catalyst is difficult to 
desorb, and it can be inferred that the difficult desorption of $\mathrm{CH}_{3} \mathrm{COOH}$ is the reason for the low activity of the $\mathrm{Zn}-\mathrm{N}-\mathrm{C}$ catalyst.

\section{Conclusions}

In summary, MOFs precursors of MOF5, TEDA-PD, and ZIF8 were prepared by the addition of different organic ligands, resulting in different microscopic morphologies. After the calcination of MOF5, TEDA-PD, and ZIF8, the Zn-O-C, Zn-O/N-C, and Zn-N-C catalysts, respectively, were obtained with the morphologies unchanged. These catalysts were successfully used for acetylene acetoxylation, with the efficiency in the sequence of $\mathrm{Zn}-\mathrm{O}-\mathrm{C}(33 \%), \mathrm{Zn}-\mathrm{O} / \mathrm{N}-\mathrm{C}(27 \%)$, and $\mathrm{Zn}-\mathrm{N}-\mathrm{C}(12 \%)$. The characterization analysis revealed that the different organic ligands and the coordination environments resulted in different electron cloud densities around the active components, which further affects the $\mathrm{CH}_{3} \mathrm{COOH}$ adsorption capacity of catalysts and the catalytic reaction activity.

Supplementary Materials: The following are available online at https://www.mdpi.com/article/ 10.3390/nano12010098/s1, Figure S1: SEM of each substance 2-MI (a), $\mathrm{H}_{2} \mathrm{BDC}(\mathrm{b}), \mathrm{H}_{2} \mathrm{BDC}\left(\mathrm{NH}_{2}\right)$ (c), $\mathrm{H}_{2} \mathrm{BDC}\left(\mathrm{NO}_{2}\right)(\mathrm{d}), \mathrm{H}_{2} \mathrm{BDC}-\mathrm{TETA}-\mathrm{PD}(\mathrm{e}), \mathrm{H}_{2} \mathrm{BDC}-\mathrm{TEDA}-\mathrm{PD}(\mathrm{f}), \mathrm{H}_{2} \mathrm{BDC}-\mathrm{PD}(5)$ (g), and $\mathrm{H}_{2} \mathrm{BDC}-\mathrm{PD}$ (13) (h). (For ease of differentiation, the catalyst in this picture was named after the added ligand.), Figure S2: Reactivity of catalysts with time. (For ease of differentiation, the catalyst in this picture was named after the added ligand.), Figure S3: XPS analysis of the contents of each element (a) and C 1s (b) of Zn-O-C, Zn-O/N-C, and Zn-N-C, Figure S4: XRD patterns in each reaction stage of Zn-O-C catalyst, Figure S5: TPD analysis of Zn-O-C and Zn-N-C catalysts for $\mathrm{CH}_{3} \mathrm{COOCHCH}_{2}$, Table S1: Specific surface area, pore volume, and pore size data of each substance.

Author Contributions: X.W. and B.D. designed and conceived of the experiments. M.L. performed the experiments. Z.X., Y.C. and G.S. analyzed the data. X.W. and B.D. contributed reagents/materials/ analysis tools. M.L. wrote the paper with direction from X.W. and B.D. All authors have read and agreed to the published version of the manuscript.

Funding: This work was financially supported by the State Key Research and Development Project of China (2016YFB03016032) and the Major Science and Technology Project of Xinjiang Bingtuan (No 2017AA007, 2020AA004).

Institutional Review Board Statement: Not applicable.

Informed Consent Statement: Not applicable.

Data Availability Statement: The data presented in this manuscript are available on request from the corresponding author.

Conflicts of Interest: The authors declare no conflict of interest.

\section{References}

1. Ping, L.I.; Feng, L.R.; Jian, L.Z.; You, K.S.; Yuan, M.J.; Qiu, F.L. A Research Summary of Vinyl Acetate Synthesis from Acetic Acid and Acetylene Catalyzed by Active Carbon-zinc Acetate. Nat. Sci. J. Hainan Univ. 2006, 9, 15886. [CrossRef]

2. Zhang, M.; Zhuang, J.; Wu, X.; Yu, Y. Experimental and theoretical insights into the cyclotrimerization of acetylene during vinyl acetate synthesis. Chem. Eng. J. 2019, 378, 122183. [CrossRef]

3. Dong, X.; Wang, Y.; Yu, Y.; Zhang, M. Density Functional Theory Investigation on the Synthesis Mechanism of Vinyl Acetate from Acetylene and Acetic Acid Catalyzed by Ordered Mesoporous Carbon-Supported Zinc Acetate. Ind. Eng. Chem. Res. 2018, 57, 7363-7373. [CrossRef]

4. Xing, B.; Wei, Z.; Wang, G. Acetate coverage effect on the reactivity of vinyl acetate synthesis on Pd/Au alloy surfaces. J. Energy Chem. 2013, 671, 600893. [CrossRef]

5. Wang, Z.; Xia, C.; Xia, Y. Dynamic relationship between environmental regulation and energy consumption structure in China under spatiotemporal heterogeneity. Sci. Total Environ. 2020, 738, 140364. [CrossRef]

6. Guo, X.L.; Chen, G.H.; Jian-Long, L.I. Study on Bamboo-Derived Activated Carbon as Catalyst Support for Vinyl Acetate Synthesis Using Acetic Acid and Acetylene. J. Chem. Eng. Chin. Univ. 2017, 31, 420-427. [CrossRef]

7. Boehm, H.P. Some aspects of the surface chemistry of carbon blacks and other carbons. Carbon 1994, 32, 759-769. [CrossRef]

8. Hoang, K.; Bong, H.; Huu, B.; Kurlyandskaya, A. Regularities of adsorption of zinc acetate from aqueous solutions onto the surface of modified activated carbons. Russ. J. Appl. Chem. 2014, 11, 104. [CrossRef] 
9. Zhang, Z.; Qu, W.; Peng, J.; Zhang, L.; Ma, X.; Zhang, Z.; Li, W. Comparison between microwave and conventional thermal reactivations of spent activated carbon generated from vinyl acetate synthesis. Desalination 2009, 249, 247-252. [CrossRef]

10. He, P.; Wu, X.; Huang, L.; Zhu, M.; Dai, B. Acetoxylation of acetylene to vinyl acetate monomer over bimetallic Zn-Ni/AC catalysts. Catal. Commun. 2018, 112, 22. [CrossRef]

11. He, P.; Huang, L.; Wu, X.; Xu, Z.; Zhu, M.; Wang, X.; Dai, B. A Novel High-Activity Zn-Co Catalyst for Acetylene Acetoxylation. Catalysts 2018, 8, 239. [CrossRef]

12. Miyazawa, S. Metal Oxide Catalyzer for Vinyl Acetate Synthesis. J. Soc. Chem. Ind. Jpn. 1958, 61, 614-618. [CrossRef]

13. Miyazawa, S. The Prevention of the Activity Decrease of Metallic Oxide Catalyst in Synthetic Process of Vinyl Acetate. J. Soc. Chem. Ind. Jpn. 1963, 66, 39-44. [CrossRef]

14. He, P.; Wang, X.; Dai], B. Zinc acetate supported on N-doped activated carbon as catalysts for acetylene acetoxylation. Chem. Eng. J. 2017, 11, 1542 .

15. Hou, C.; Feng, L.; Li, Z.; Wang, Z.; Qiu, F. Mechanism of Carboxyl and Carbonyl Groups in Carrier Surface of Catalyst for Vinyl Acetate Synthesis. Acta Chim. Sin. Chin. Ed. 2009, 67, 1528-1532. [CrossRef]

16. Zhu, F.; Zhu, M.; Kang, L. B-doped activated carbon as a support for a high-performance Zn-based catalyst in acetylene acetoxylation. Green Energy Environ. 2020, 12, 27. [CrossRef]

17. Hou, C.Y.; Feng, L.R.; Qiu, F.L. Highly active catalyst for vinyl acetate synthesis by modified activated carbon. Chin. Chem. Lett. 2009, 20, 865-868. [CrossRef]

18. Kitao, T.; Zhang, Y.; Kitagawa, S.; Wang, B.; Uemura, T. Hybridization of MOFs and polymers. Chem. Soc. Rev. 2017, 46, 3108. [CrossRef] [PubMed]

19. Islamoglu, T.; Goswami, S.; Li, Z.; Howarth, A.J.; Farha, O.K.; Hupp, J.T. Postsynthetic Tuning of Metal-Organic Frameworks for Targeted Applications. Acc. Chem Res. 2017, 50, 805-813. [CrossRef]

20. Sule, R.; Mishra, A.K.; Nkambule, T.T. Recent advancement in consolidation of MOFs as absorbents for hydrogen storage. Int. J. Energy Res. 2021, 12, 6608. [CrossRef]

21. Gu, C.; Yu, Z.; Liu, J.; Sholl, D.S. Construction of an Anion-Pillared MOF Database and the Screening of MOFs Suitable for Xe/Kr Separation. ACS Appl. Mater. Interfaces 2021, 13, 11039-11049. [CrossRef]

22. Thakur, B.; Karve, V.V.; Sun, D.T.; Semrau, A.L.; Weiß, L.J.K.; Grob, L.; Fischer, R.A.; Queen, W.L.; Wolfrum, B. An Investigation into the Intrinsic Peroxidase-Like Activity of Fe-MOFs and Fe-MOFs/Polymer Composites. Adv. Mater. Technol. 2021, 11, 2001048. [CrossRef]

23. Yang, G.-L.; Jiang, X.-L.; Xu, H.; Zhao, B. Applications of MOFs as Luminescent Sensors for Environmental Pollutants. Small 2021, 13, 2005327. [CrossRef]

24. Kampouri, S.; Ebrahim, F.M.; Fumanal, M.; Nord, M.; Schouwink, P.A.; Elzein, R.; Addou, R.; Herman, G.S.; Smit, B.; Ireland, C.P.; et al. Enhanced Visible-Light-Driven Hydrogen Production through MOF/MOF Heterojunctions. ACS Appl. Mater. Interfaces 2021, 13, 14239-14247. [CrossRef]

25. He, H.; Li, R.; Yang, Z.; Chai, L.; Jin, L.; Alhassan, S.I.; Ren, L.; Wang, H.; Huang, L. Preparation of MOFs and MOFs derived materials and their catalytic application in air pollution: A review. Catal. Today 2020, 45, 33. [CrossRef]

26. Sedahmed, O.; Arumugam, S.R.; Pan, J.; Wei, L. Highly activated porous carbon with 3D microspherical structure and hierarchical pores as greatly enhanced cathode material for high-performance supercapacitors. J. Power Sources 2018, 391, 162-169. [CrossRef]

27. Kimitsuka, Y.; Hosono, E.; Ueno, S.; Zhou, H.; Fujihara, S. Fabrication of Porous Cubic Architecture of ZnO Using Zn-terephthalate MOFs with Characteristic Microstructures. Inorg. Chem. 2013, 52, 14028-14033. [CrossRef]

28. Lin, Y.; Wan, H.; Wu, D.; Chen, G.; Zhang, N.; Liu, X.; Li, J.; Cao, Y.; Qiu, G.; Ma, R. Metal-Organic Framework Hexagonal Nanoplates: Bottom-up Synthesis, Topotactic Transformation, and Efficient Oxygen Evolution Reaction. J. Am. Chem. Soc. 2020, 142, 7317-7321. [CrossRef] [PubMed]

29. Zhao, J.; Quan, X.; Chen, S.; Liu, Y.; Yu, H. Cobalt Nanoparticles Encapsulated in Porous Carbons Derived from Core-Shell ZIF67@ZIF8 as Efficient Electrocatalysts for Oxygen Evolution Reaction. ACS Appl. Mater. Interfaces 2017, 9, 28685-28694. [CrossRef] [PubMed]

30. Li, M.; Huang, W.; Tang, B.; Song, F.; Lv, A.; Ling, X. Preparation of a Composite Material AC/Cu-BTC with Improved Water Stability and n-Hexane Vapor Adsorption. J. Nanomater. 2019, 2019, 5429364. [CrossRef]

31. Lestari, W.W.; Wibowo, A.H.; Astuti, S.; Irwinsyah; Pamungkas, A.Z.; Krisnandi, Y.K. Fabrication of hybrid coating material of polypropylene itaconate containing MOF-5 for $\mathrm{CO}_{2}$ capture. Prog. Org. Coat. 2018, 115, 49-55. [CrossRef]

32. Jiang, M.; Cao, X.; Zhu, D.; Duan, Y.; Zhang, J. Hierarchically Porous N-doped Carbon Derived from ZIF-8 Nanocomposites for Electrochemical Applications. Electrochim. Acta 2016, 196, 699-707. [CrossRef]

33. Wu, Y.; Pang, H.; Yao, W.; Wang, X.; Yu, S.; Yu, Z.; Wang, X. Synthesis of rod-like metal-organic framework (MOF-5) nanomaterial for efficient removal of $\mathrm{U}(\mathrm{VI})$ : Batch experiments and spectroscopy study. Sci. Bull. 2018, 63, 831-839. [CrossRef]

34. Li, X.; Wang, L.; Li, X.; Zhang, J.; Wang, M.; Che, R. Multi-dimensional ZnO@MWCNTs assembly derived from MOF-5 heterojunction as highly efficient microwave absorber. Carbon 2021, 172, 15-25. [CrossRef]

35. Liu, Z.; Wu, A.; Yan, H.; Su, D.; Jin, C.; Guo, H.; Wang, L.; Tian, C. An effective "precursor-transformation" route toward the high-yield synthesis of ZIF-8 tubes. Chem. Commun 2020, 56, 2913-2916. [CrossRef] 
36. Karakawa, M.; Sugahara, T.; Hirose, Y.; Suganuma, K.; Aso, Y. Thin Film of Amorphous Zinc Hydroxide Semiconductor for Optical Devices with an Energy-Efficient Beneficial Coating by Metal Organic Decomposition Process. Sci. Rep. 2018, 8, 10839. [CrossRef]

37. Pant, A.; Tanwar, R.; Kaur, B.; Mandal, U.K. A magnetically recyclable photocatalyst with commendable dye degradation activity at ambient conditions. Sci. Rep. 2018, 8, 14700. [CrossRef] [PubMed]

38. Dai, L.P.; Deng, H.; Chen, G.; Tang, C.F.; Wei, M.; Li, Y. Growth of a-b-axis orientation ZnO films with zinc vacancies by SSCVD. Vacuum 2007, 81, 969-973. [CrossRef]

39. Abdalla, A.; Bereznev, S.; Spalatu, N.; Volobujeva, O.; Sleptsuk, N.; Danilson, M. Pulsed laser deposition of Zn(O,Se) layers in nitrogen background Pressure. Sci. Rep. 2019, 9, 17443. [CrossRef] [PubMed]

40. Dupin, J.C.; Vinatier, P.; Levasseur, A. Systematic XPS Studies of Metal Oxides, Hydroxides and Peroxides. Phys. Chem. Chem. Phys. 2000, 2, 1319-1324. [CrossRef]

41. Artyushkova, K. Misconceptions in interpretation of nitrogen chemistry from x-ray photoelectron spectra. J. Vac. Sci. Technol. A Vac. Surf. Film. 2020, 38, 031002. [CrossRef]

42. Kovács, I.; Iost, N.; Solymosi, F. Thermal and photo-induced dissociation of $\left(\mathrm{C}_{2} \mathrm{H}_{5}\right)_{2} \mathrm{Zn}$ to yield $\mathrm{C}_{2} \mathrm{H}_{5}$ on the $\mathrm{Pd}(100)$ surface. $J$. Chem. Phys. 1994, 101, 4236-4247. [CrossRef] 